\title{
Isotropic thermal expansion in anisotropic thermal management composites filled with carbon fibres and graphite.
}

\author{
Valerio Oddone ${ }^{1, *}$, Jakob Segl ${ }^{2}$, Mythili Prakasam ${ }^{3}$, Martin T. Hartmann ${ }^{1}$, \\ Jean-François Silvain ${ }^{3}$, Christian Edtmaier ${ }^{2}$, and Stephanie Reich ${ }^{1}$ \\ ${ }^{1}$ Department of Physics, Freie Universität Berlin, Arnimallee 14, 14195 Berlin, Germany \\ ${ }^{2}$ Institute of Chemical Technologies and Analytics, Vienna University of Technology, Getreidemarkt 9/164-CT, 1060 \\ Wien, Austria \\ ${ }^{3}$ Institute for Solid State Chemistry Bordeaux, CNRS, 87 Avenue du Docteur Albert Schweitzer, 33608 Pessac, France \\ *Corresponding author. E-mail address: valerio.oddone@gmail.com
}

Light materials with high thermal conductivity and low thermal expansion have a wide application potential for the thermal management of high performance electronics, in particular in mobile and aerospace applications. We present here metal matrix composites with a mixture of graphite flakes and pitch based carbon fibres as filler. The production by Spark Plasma Sintering orients the filler particles on to a plane perpendicular to the pressing axis. The obtained materials have lower density than aluminium combined with a thermal conductivity significantly outperforming the used metal matrix. Depending on the ratio of the filler components, a low thermal expansion along the pressing direction (high graphite flakes content) or across the pressing direction (high carbon fibre content) is achieved. For a 1:3 ratio of carbon fibres to graphite we measured an isotropic reduction of the thermal expansion of the matrix by up to $55 \%$. We present a detailed characterisation of composites with two aluminium alloys as matrix and an overview of the properties for six different metal matrices including magnesium and copper. With the goal of a technical application, we show that the described properties are intrinsic to the material compositions and are achieved with a wide spectrum of production methods.

Keywords: metal matrix composites, isotropic, graphite, thermal conductivity, thermal expansion, carbon fibres

\section{Introduction}

The growing performance and power density of electronic components makes heat dissipation challenging $[1,2]$. Ideal thermal dissipation via heat sinks is achieved by a direct contact with the cooled components without an interlayer of thermal paste. However, for a direct contact the low coefficient of 
thermal expansion (CTE) of electronic components must match the CTE of the heat sink [1-3], a condition that cannot be fulfilled by common metals such as copper and aluminium. Metal matrix composites with high thermal conductivity (TC) and low CTE were proposed in several research works as high performance heat sinks, mostly combining highly conducting metal matrices with graphite [412] or carbon fibres [3, 13-16] fillers, which have high TC and low CTE in a plane or along the axis. The highest TC values were obtained using macroscopic fillers with low surface/volume ratio in order to minimise the effect of the interface thermal resistance [17]. Three-phases and four-phases composites with fibres and flakes mixtures were reported for the mechanical reinforcement of polymers [18-20], however rarely in a metal matrix for the control of the thermal properties. Prieto et al [21] reported composites produced by gas pressure infiltration with Al-12Si matrix and 88vol\% of carbon fibres and other particles, including graphite flakes. A two-directional reduction of the CTE was reported.

In previous studies we analysed the thermal properties of metal matrix composites produced by spark plasma sintering (SPS). The uniaxial pressing of the SPS oriented the filler particles leading to anisotropic thermal properties. The TC increased in a plane perpendicular to the force direction (x,yplane) and decreased along the direction of force (z-axis). The CTE was dependent on the filler geometry: using carbon fibres as a filler we reduced the CTE in the $\mathrm{x}, \mathrm{y}$-plane down to $3 \mathrm{ppm} \mathrm{K}^{-1}$ [16], whereas with graphite flakes as a filler we obtained a CTE along the z-axis as low as -10 ppm $\mathrm{K}^{-1}$ [911]. The CTE reduction for carbon fibres composites is explained by the low axial CTE and high modulus of the fibres. The z-axis CTE of the graphite-metal composites is lower than the z-axis CTE of both matrix and filler, which cannot be explained by a rule of mixture. This effect is object of intensive studies and we attributed it to a macroscopic stretch of slightly folded graphite flakes by the expanding matrix [11]. Due to its high elasticity modulus, we exclude a significant strain in the crystal lattice of graphite.

In this paper, we present composites with a mixture of graphite and carbon fibres as fillers to tune a reduced CTE along one, two or three axes. We showed the effect of substituting part of the filler with silicon to have higher isotropy and compared various metal matrices to optimise selected parameters. Heat sinks have different geometries depending on the device they are mounted on. The composition of the presented material can be tuned in order to have a low CTE parallel to the interface with the cooled component and high TC in direction the heat shall be dissipated. Further, the high flexibility in the thermal design might allow further applications.

For one combination of filler and matrix we discuss in detail the effect of variations of the production parameters. Sinter pressure, temperature and heating rates are found to have minimal influence on the 
thermal properties of the obtained composite, which is essential for use of the material beyond the lab scale. The special conditions obtained by Spark Plasma Sintering (high heating rates, electrical current flow through the sample) are not essential for the sintering of aluminium. Simpler powder metallurgy methods like hot pressing, in spite of the lower heating rates, may be used to sinter materials with similar thermal properties.

\section{Materials and methods}

Metal matrix composites were sintered by SPS starting from mixtures of metal alloy powders with $35 \%$ or $50 \%$ volume concentration of graphite flakes $(\mathrm{Gr})$ and carbon fibres (CF). For all materials, density, TC, CTE and tensile strength were measured (Paragraph 3.3, Table 1).

\subsection{Preparation of the powder mixtures}

The following metal powders were used as matrices for the composites:

- Aluminium alloy Al2024, (Al-4.4Cu-0.6Mn-1.4Mg, $50 \mu \mathrm{m})$, Ecka Granules, Germany

- Metal powder mixture Alumix 231, (Al-14Si-2.5Cu-0.5Mg, $50 \mu \mathrm{m})$, Ecka Granules, Germany

- Metal powder mixture Alumix 431, (Al-5.5Zn-2.5Mg-1.5Cu, $50 \mu \mathrm{m}$ ), Ecka Granules, Germany

- Aluminium powder $(50 \mu \mathrm{m})$, Ecka Granules, Germany

- Magnesium alloy Mg-0.9Ca, Helmholtz-Zentrum Geesthacht, Germany

- Copper powder (3 $\mu \mathrm{m}$, dentritic), Sigma Aldrich, US

Al2024 and Mg-0.9Ca are prealloyed powders, while Alumix 231 and Alumix 431 are mixtures of pure metals that form the alloy in the sintering process.

The following highly thermally conducting fillers were used:

- Large graphite flakes Ma3095, (500 x $10 \mu \mathrm{m})$, NGS Naturgraphit, Germany

- Milled pitch based carbon fibres, XN100-25M, $(250 \times 10 \mu \mathrm{m})$, Nippon Graphite Fiber Corporation, Japan

Crystalline graphite can have an in-plane TC as high as $2000 \mathrm{~W} \mathrm{~m}^{-1} \mathrm{~K}^{-1}$ [22]. The used CF have an axial TC of $900 \mathrm{~W} \mathrm{~m}^{-1} \mathrm{~K}^{-1}$ (supplier data), which is two orders of magnitude higher than the TC of common polyacrylonitril-based CF [23]. Moreover, pitch based CF have higher elasticity moduli than PAN-based $\mathrm{CF}$. The in-plane CTE of the graphite and the axial CTE of the CF is approximately $-1 \mathrm{ppm} \mathrm{K}^{-1}$.

The powders were gently mixed in a mortar for few minutes, avoiding damage of the fibres and excessive oxidation of the metals. Mechanical mixing of the powders by ball milling could be used only for copper-graphite mixtures [9], while it deteriorated the thermal properties of the composites with light metal matrix and with CF filler.

\subsection{Standard samples preparation}


The composites were produced by SPS in a Dr. Sinter 211-Lx (experimental setup in the supplementary material S1). Cylindrical samples with $6 \mathrm{~mm}$ diameter and 4-5 $\mathrm{mm}$ height and disc-shaped samples with $25 \mathrm{~mm}$ diameter and 1-2 $\mathrm{mm}$ thickness were sintered with the following parameters:

- Temperature: $500^{\circ} \mathrm{C}$ (Alumix 231), $550^{\circ} \mathrm{C}\left(\mathrm{Al} 2024\right.$, Alumix 431), $600^{\circ} \mathrm{C}(\mathrm{Al}, \mathrm{Mg}-0.9 \mathrm{Ca}, \mathrm{Cu})$

- Heating rate: $100-50 \mathrm{~K} \mathrm{~min}^{-1}$ (cylindrical samples), 50-20 $\mathrm{K} \mathrm{min}^{-1}$ (disc-shaped samples), the reduced rate was used for the last $100 \mathrm{~K}$ before reaching the maximal temperature.

- Holding time at the maximal temperature: 2-4 minutes.

- Applied uniaxial pressure: $50 \mathrm{MPa}$

- Atmosphere: vacuum of $1 \mathrm{~Pa}$

- Heat treatment after sintering: $2 \mathrm{~h}$ at $350^{\circ} \mathrm{C}(\mathrm{Al}, \mathrm{Mg}-0.9 \mathrm{Ca}), \mathrm{T} 6$ for the aluminium alloys $(2 \mathrm{~h}$ at $490^{\circ} \mathrm{C}$, water quenching, $12 \mathrm{~h}$ at $190^{\circ} \mathrm{C}$ for $\mathrm{A} 12024 ; 2 \mathrm{~h}$ at $480^{\circ} \mathrm{C}$, warm water quenching and $12 \mathrm{~h}$ at $180^{\circ} \mathrm{C}$ for Alumix 231 and Alumix 431)

For aluminium and magnesium alloys, the highest possible sintering temperature was chosen to optimise the densification and TC since the strong oxide layer of the metal powders must be overcome. High heating rates were chosen since they should limit the grain growth in the metal matrix [24-26], which helps achieving the optimal strength [27].

The degree of alignment of the fillers on the $\mathrm{x}, \mathrm{y}-$ plane is dependent on the compression ratio, i.e. the ratio between the density of the powder mixture and the density of the sintered sample [16]. The structure of a sample section is visible in Fig. 1.

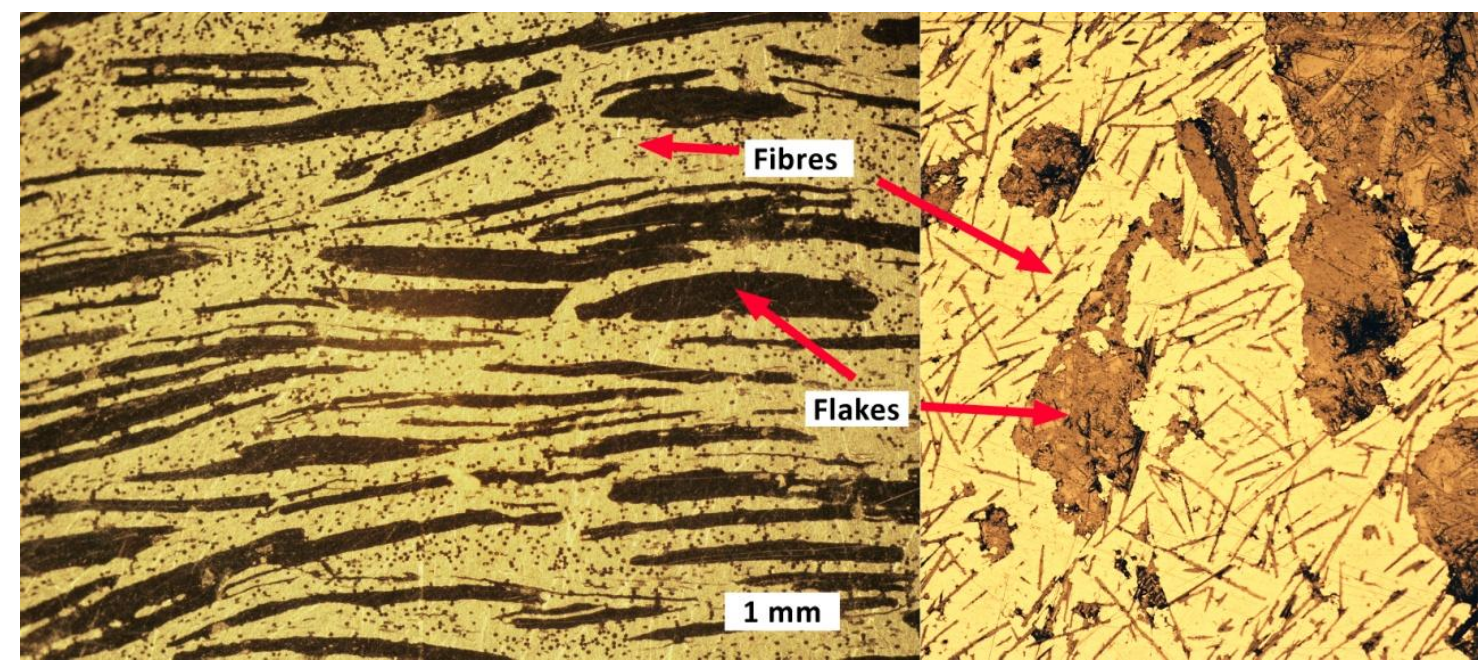

Fig. 1 Micrographs of a composite showing the planar distribution of dark carbon fibres and graphite in the bright aluminium alloy matrix. Side view (left, dark field, perpendicular to the x,y-plane) and top-view (right, bright field, parallel to the $\mathrm{x}, \mathrm{y}$-plane). Composition: Al2024 matrix with 50vol\% of filler mixture, 1:3 ratio of carbon fibres to graphite.

\subsection{Sample preparation for production method comparison}


For the material composition with A12024 matrix and 50vol\% mixture of carbon fibres and graphite in 1:3-ratio, we produced samples with a wide range of sinter parameters (temperature of $400-550^{\circ} \mathrm{C}$, pressure of 2-50 MPa, variable pressure profiles, heating rates of $10-100 \mathrm{~K} \mathrm{~min}^{-1}$, no current flow, samples with 0.3-6 g mass). Samples with identical compositions were produced by hot-pressing in a self-built set up with a temperature of $470^{\circ} \mathrm{C}$, holding time of $30 \mathrm{~min}$ and pressure of $60 \mathrm{MPa}$. After fabrication the samples had a cylindrical shape with $10-20 \mathrm{~mm}$ diameter and 4-5 $\mathrm{mm}$ height. For dilatometry measurements cubes of $4-5 \mathrm{~mm}$ side were cut. The thermal conductivity was measured on discs with $20 \mathrm{~mm}$ diameter and $5 \mathrm{~mm}$ thickness.

\subsection{Characterisation}

Thermal diffusivity was measured on the disc-shaped samples by the flash method with a Netzsch LFA447 NanoFlash (details in the supplementary material S2). In plane measurements (thermal diffusivity in the x,y-plane) were performed by the radial heat flow method for thin samples [28] and by cutting thick samples to slices ( $3 \mathrm{~mm}$ in thickness). The TC was obtained by multiplication of the measured thermal diffusivity with the specific heat capacity and the density, determined, respectively, by the rule of mixture and the geometric method (details in the supplementary material S3). For one composite, the temperature evolution of the $\mathrm{TC}$ was measured between $20^{\circ} \mathrm{C}$ and $110^{\circ} \mathrm{C}$. CTE measurements were performed with the cylindrical samples in a dilatometer Linseis L75XH1000. We performed four cycles between $40^{\circ} \mathrm{C}$ and $150{ }^{\circ} \mathrm{C}$ with a heating rate of $1 \mathrm{~K} \mathrm{~min}^{-1}$.

The tensile strength was measured in $\mathrm{x}, \mathrm{y}$-direction with a Zwick Z010 tensile tester. The disc-shaped samples were manually milled to a dog-bone shape with a width of $5 \mathrm{~mm}$ and a gage length of $8 \mathrm{~mm}$ as previously shown for graphite-metal composites [11], by which we also demonstrate the machinability of the composites.

The aluminium carbide content of the composite was determined by gas chromatography-mass spectrometry (GC-MS) measurements. Aluminium carbide is in limited amounts essential for the bonding between filler and matrix, but large amounts may deteriorate the thermal properties of the composite. For the CG-MS measurements the composite material was dissolved in $\mathrm{NaOH}$ solution and the methane amount emitted during the hydrolysis of aluminium carbide, according to Equation 1, was measured by a Shimadzu GCMS-QP2010 Plus. The method is described in more detail by Segl et al [29].

$$
\mathrm{Al} 4 \mathrm{C} 3+4 \mathrm{NaOH}+12 \mathrm{H} 20 \rightleftharpoons 4 \mathrm{Na}+\mathrm{Al}(\mathrm{OH}) 4-+3 \mathrm{CH} 4 \uparrow
$$

Eq. 1: Hydrolysis reaction of aluminium carbide with sodium hydroxide to form methane

\section{Results and discussion}


We previously characterised composites with graphite flakes [11] and pitch based CF [16] in different concentrations between $0 \mathrm{vol} \%$ and $65 \mathrm{vol} \%$. In this study we present the results about composites with a fixed filler concentration of $35 \mathrm{vol} \%$ or $50 \mathrm{vol} \%$ with variable CF:Gr-ratio. A high graphite flakes content reduces the z-CTE [11], while a high CF content reduces the $\mathrm{x}, \mathrm{y}-\mathrm{CTE}$ [16]. Combining the two fillers materials with intermediate properties are produced. We present detailed results for the aluminium alloys Al2024 and Alumix 231, as well as an overview about four further metal matrices for an optimisation of single parameters. Finally, we discuss the effect of different production parameters on composites with Al2024 matrix and 50vol\% filler with 1:3 CF:Gr-ratio. It shall be noticed that the CTE was measured directly, while the TC was derived from the thermal diffusivity as described in Section 2.4 and in the supplementary material S3.

\subsection{Al2024 matrix}

The TC and CTE for composites with A12024 matrix and 50vol\% of variable proportions of carbon fibres and graphite flakes are plotted in Fig. 2. Clearly, the TC of the matrix $\left(130 \mathrm{~W} \mathrm{~m}^{-1} \mathrm{~K}^{-1}\right)$ for the sintered powder) was increased by both fillers in $\mathrm{x}, \mathrm{y}$-direction and decreased in $\mathrm{z}$-direction. The CTE of the matrix $\left(24.7 \mathrm{ppm} \mathrm{K}^{-1}\right.$ ) was decreased in $\mathrm{x}, \mathrm{y}$-direction by the carbon fibres and in $\mathrm{z}$-direction by the graphite flakes, whereby isotropy in CTE was achieved at approximately 1:3 CF:Gr-ratio. Hereby, the volumetric CTE increased from $35 \mathrm{ppm} \mathrm{K}^{-1}$ for $\mathrm{CF}$ filler to a maximum of $40 \mathrm{ppm} \mathrm{K}^{-1}$ at 2:2 CF:Gr-ratio down to $27 \mathrm{ppm} \mathrm{K}^{-1}$ for Gr filler. All values are well below the $75 \mathrm{ppm} \mathrm{K}^{-1}$ of the matrix material.

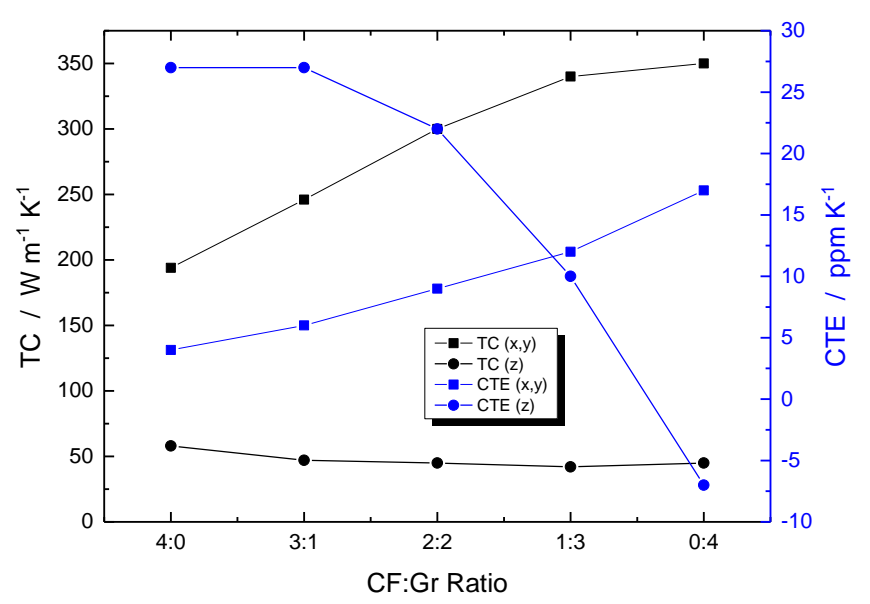

Fig. 2. TC and CTE for composites with Al2024 matrix as a function of the CF:Gr-ratio.

The tensile strength measured in the $\mathrm{x}, \mathrm{y}$-plane ranged from 40 to $50 \mathrm{MPa}$, independently from the CF:Gr-ratio. An exception were the samples with pure graphite filler, which achieved only $25 \mathrm{MPa}$. 
Since the CF are smaller than the graphite flakes, the composites with high CF concentration were more homogeneous and easier to machine in small and thin shapes.

\subsection{Alumix 231 matrix}

In order to reduce the anisotropy and increase the strength for all filler compositions, a second series of measurements was performed with Alumix 231 matrix (Fig. 3). The high silicon content (14\%) of this metal powder mixture reduces its CTE to $18.5 \mathrm{ppm} \mathrm{K}^{-1}$, therefore a filler concentration of $35 \mathrm{vol} \%$ was sufficient to achieve a similar CTE to other aluminium alloys at 50vol\% filler concentration. A lower filler concentration leads to a higher isotropy of the composite. Similarly to the composites with Al2024 matrix, for a CF:Gr-ratio of approximately 1:3 isotropic CTE was achieved. The volumetric CTE remained approximately constant with a maximum of $45 \mathrm{ppm} \mathrm{K}^{-1}$ at 3:1 CF:Gr-ratio and a minimum of $38 \mathrm{ppm} \mathrm{K}^{-1}$ for only $\mathrm{Gr}$ filler. The pure Alumix 231 matrix has $55 \mathrm{ppm} \mathrm{K}^{-1}$.

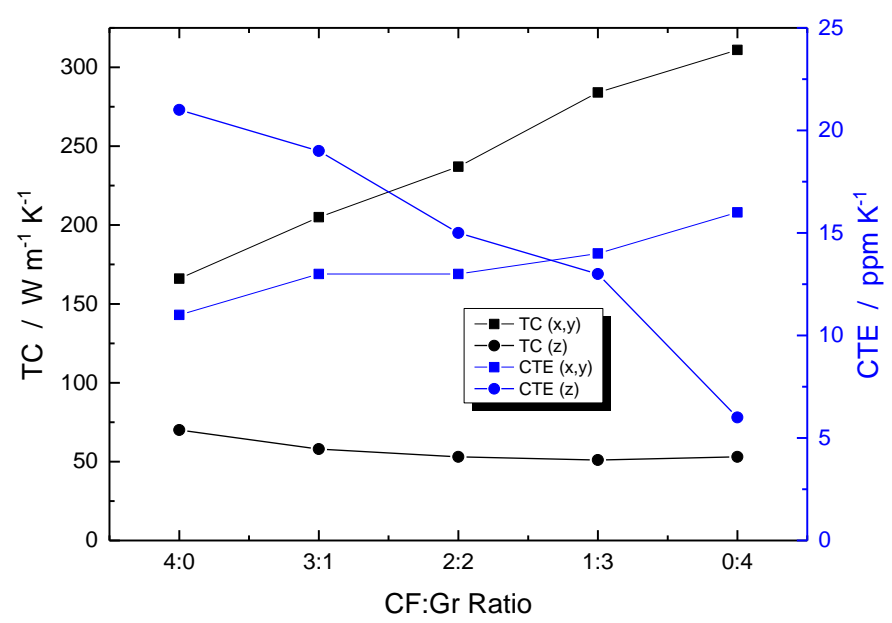

Fig. 3. TC and CTE for composites with Alumix 231 matrix as a function of the CF:Gr-ratio.

Thanks to the lower filler concentration we measured for these composites significantly higher tensile strengths of 60-95 MPa. No clear correlation was observed to the CF:Gr-ratio.

\subsection{Metal matrix comparison}

Using the 1:3 CF:Gr ratio and 50vol\% filler concentration, we characterised further composites with different metal matrices in order to optimise different parameters. In particular, we achieved higher TC with pure aluminium and copper, the lowest density with $\mathrm{Mg}-0.9 \mathrm{Ca}$ matrix (hereby the calcium improved the sinterability of the magnesium powder [30]). Clearly, copper outperformed the other light metal matrices in most parameters since it has higher TC, lower CTE and better sintering properties, but the density of its composites are over twice as high. With the Alumix 431 mixture, which has a similar 
composition to the $7 \mathrm{xxx}$ high performance aluminium-zinc alloys, we did not achieve the highest strength, differently from our previous results with graphite flakes as a filler [11]. The results for all matrices are summarised in Table 1.

Table 1. Comparison of the properties of composites with different metal matrices and 50vol\% of 1:3 CF:Gr as filler (35vol\% for Alumix 231). The parameter marked in red was optimised.

\begin{tabular}{|c|c|c|c|c|c|c|}
\hline & Al2024 & Alumix 231 & Alumix 431 & Aluminium & Mg-0.9Ca & Copper \\
\hline $\mathrm{TC}(\mathbf{x}, \mathbf{y}) / \mathrm{W} \mathrm{m}^{-1} \mathbf{K}^{-1}$ & 340 & 285 & 335 & 390 & 370 & 495 \\
\hline $\mathbf{T C}(\mathbf{z}) / \mathbf{W} \mathbf{m}^{-1} \mathbf{K}^{-1}$ & 42 & 51 & 39 & 45 & 42 & 71 \\
\hline CTE $(x, y, z) / p p m K^{-1}$ & 11 & 14 & 12 & 19 & 15 & 12 \\
\hline Density / $\mathbf{k g ~ m}^{3}$ & 2370 & 2450 & 2400 & 2300 & 1950 & 5400 \\
\hline Tensile strength / MPa & 46 & 80 & 38 & 13 & 38 & 63 \\
\hline
\end{tabular}

\subsection{Production methods}

For a wide technical application of a material it is helpful if the needed physical properties are not derived from a very specific production process, but are intrinsic to the material itself. We chose the composite with Al2024 matrix and 50vol\% filler with 1:3 CF:Gr-ratio to investigate the effect of variations in the production parameters.

For a more complete characterisation of this material, a temperature dependent TC measurement was performed (Table 2). The thermal diffusivity was measured at four different temperatures and multiplied with the respective density and specific heat capacity to obtain the TC. We observed a slightly lower decrease in TC than in graphite [31].

Table 2. Temperature dependent TC measurements. Thermal diffusivity (TD) measured by xenon-flash, density calculated by dilatometry results, specific heat capacity $c_{p}$ calculated by rule-of-mixture from the literature values for A12024 [32] and graphite [33].

\begin{tabular}{|c|c|c|c|c|}
\hline Temperature & $\mathrm{TD}(\mathrm{x}, \mathrm{y} / \mathrm{z}) / \mathrm{mm}^{2} \mathrm{~s}$ & Density / $\mathrm{kg} \mathrm{m}^{-3}$ & $c_{p} / \mathrm{J} \mathrm{kg}^{-1} \mathrm{~K}^{-1}$ & $\mathrm{TC}(\mathrm{x}, \mathrm{y} / \mathrm{z}) / \mathrm{J} \mathrm{m}^{-1} \mathrm{~K}^{-1}$ \\
\hline $20^{\circ} \mathrm{C}$ & $179 / 21.3$ & 2370 & 799 & $339 / 40.3$ \\
\hline $5^{\circ} \mathrm{C}$ & $172 / 19.4$ & 2368 & 843 & $343 / 38.8$ \\
\hline $80^{\circ} \mathrm{C}$ & $155 / 17.9$ & 2366 & 887 & $326 / 37.6$ \\
\hline $110^{\circ} \mathrm{C}$ & $131 / 17.0$ & 2364 & 931 & $293 / 37.5$ \\
\hline
\end{tabular}

In the following production method comparison, we showed that the high heating rates and the current flow of the SPS are not necessary to achieve the optimal thermal properties. Instead, simpler production techniques such as hot-pressing are sufficient. The theoretical density of the analysed material is $2490 \mathrm{~kg} \mathrm{~m}^{-3}$. The experimentally measured densities range between $2350 \mathrm{~kg} \mathrm{~m}^{-3}$ and $2430 \mathrm{~kg} \mathrm{~m}^{-3}$ for 
most production methods. No clear correlation was observed to the sintering parameters nor to the thermal properties. Only for samples sintered below $500^{\circ} \mathrm{C}$ or below $10 \mathrm{MPa}$ pressure the densities reduced to $2260 \mathrm{~kg} \mathrm{~m}^{-3}$, which resulted in higher porosity and lower TC.

In the first experiment series we investigated the effect of the heating rate (HR) and of the current flow. In order to simulate the hot pressing in the SPS system keeping the other parameters unchanged, we reduced the HR from 50-20 $\mathrm{K} \mathrm{min}^{-1}$ (disc-shaped sample) or 100-50 $\mathrm{K} \mathrm{min}^{-1}$ (cylindrical samples) to 20$10 \mathrm{~K} \mathrm{~min}^{-1}$ in the heating phase (up to $450^{\circ} \mathrm{C}$ and $450-550^{\circ} \mathrm{C}$ ) and limited it to $-30 \mathrm{~K} \mathrm{~min}^{-1}$ in the cooling phase (Low HR). Further, we coated the graphite crucible with boron nitride (BN) to avoid the current flow through the sample. Finally, we increased the holding time at the maximal temperature to $30 \mathrm{~min}$. We observed little influence of the HR and current flow, as visible in Table 3. Longer sintering times slightly improved the TC. With the same powder, samples were produced by standard hot-pressing with slightly different parameters $\left(470^{\circ} \mathrm{C}, 60 \mathrm{MPa}, 30 \mathrm{~min}\right)$. Again, both the $\mathrm{TC}$ and the CTE remained mostly unchanged. These samples had different shapes and were milled for the thermal characterisation. This might have degraded the inner structure, which explains the slightly higher CTE of the hot-pressed composite.

Table 3. Simulation of the hot-pressing conditions in a SPS system by reduction of the heating rate (HR), interruption of the current flow by boron nitride coating $(\mathrm{BN})$ and increase of the holding time at maximal temperature to 30 minutes. Comparison with samples produced by hot-pressing. Effect on the TC, CTE and density of the composites.

\begin{tabular}{lllll}
\hline & $\mathbf{T C}(\mathbf{x}, \mathbf{y}) / \mathbf{W ~ m}^{-1} \mathbf{K}^{-1}$ & $\mathbf{T C}(\mathbf{z}) / \mathbf{W ~ m}^{-1} \mathbf{K}^{-1}$ & $\mathbf{C T E}(\mathbf{x}, \mathbf{y}, \mathbf{z}) / \mathbf{p p m ~ \mathbf { K } ^ { - 1 }}$ & ${\text { Density } / \mathbf{~ k g ~ m}^{3}}^{\mathbf{3}}$ \\
\hline Standard & 330 & 43 & 12,0 & 2370 \\
Low HR & 345 & 41 & 13,5 & 2350 \\
BN coating & 330 & 41 & 12,5 & 2390 \\
Low HR + BN coating & 320 & 38 & 11,5 & 2330 \\
Standard, 30' holding & 355 & 40 & 12,5 & 2390 \\
Hot press & 345 & 51 & $12(\mathrm{x}, \mathrm{y}), 15(\mathrm{z})$ & 2430 \\
\hline
\end{tabular}

In the second experiment series we investigated the effect of the sintering temperature on the composite (Table 4). Clearly, higher temperatures had a positive effect on the densification and TC, however, between $500^{\circ} \mathrm{C}$ and $550^{\circ} \mathrm{C}$ little differences were noticed. The high temperature helps breaking the oxide layer of the aluminium powders. For comparison, in copper matrix composite similar results were observed for temperatures between 600 and $900^{\circ} \mathrm{C}$. 
Table 4. Investigation of different sintering temperatures. Effect on the TC, CTE and density of the composites.

\begin{tabular}{|c|c|c|c|c|}
\hline & $\mathrm{TC}(\mathrm{x}, \mathrm{y}) / \mathrm{W} \mathbf{m}^{-1} \mathbf{K}^{-1}$ & $\mathrm{TC}(\mathrm{z}) / \mathrm{W} \mathbf{m}^{-1} \mathrm{~K}^{-1}$ & CTE $(x, y, z) /$ ppm K ${ }^{-1}$ & Density / $\mathrm{kg} \mathrm{m}^{3}$ \\
\hline $500^{\circ} \mathrm{C}$ & 340 & 39 & 12,5 & 2370 \\
\hline $450^{\circ} \mathrm{C}$ & 295 & 38 & 12,5 & 2320 \\
\hline $400^{\circ} \mathrm{C}$ & 205 & 24 & 13,0 & 2260 \\
\hline
\end{tabular}

Very low heating rates, long holding times and high process temperatures increase the probability aluminium carbide production at the matrix-filler interface, which harms the physical properties of the composite $[34,35]$. On the other hand, the carbide layer might enhance the contact between matrix and filler, as was reported for Al-CNT composites [36]. Although the correlation with the sinter parameters is clear, the $\mathrm{Al}_{4} \mathrm{C}_{3}$ concentration in our composites is not significant (Table 5). These results are supported by the findings of Etter et al. [37], who neither found significant amounts of Al4C3 in graphite/aluminium composites produced by gas pressure infiltration at temperatures of $670{ }^{\circ} \mathrm{C}$. Therefore it could be shown, that excessive $\mathrm{Al}_{4} \mathrm{C}_{3}$ formation is of no concern for solid state processing routes, in contradiction to liquid state processing [38].

Table 5. Aluminium carbide concentration for different production parameters.

\begin{tabular}{llll}
\hline Sinter temperature $/{ }^{\circ} \mathbf{C}$ & Heating rate $/ \mathbf{K ~} \mathbf{~ m i n}^{-\mathbf{1}}$ & Holding time / min & Carbide concentration / ppm \\
\hline $\mathbf{5 0 0}$ & $50-20$ & 2 & 0.75 \\
$\mathbf{5 5 0}$ & $50-20$ & 2 & 0.89 \\
$\mathbf{5 5 0}$ & $20-10$ & 2 & 1.05 \\
$\mathbf{5 5 0}$ & $50-20$ & 30 & 0.98 \\
\hline
\end{tabular}

In the third experiment series we investigated the effect of the SPS pressure (uniaxial pressure on the powders). We tried to apply the pressure only during the heating phase and to release it at the beginning of the cooling phase (50-50-2 MPa), alternatively to release it before the heating phase, similarly to traditional powder metallurgy processes (50-2-2 MPa), in which the powders are pressed and heated in two steps. Eventually we repeated the sinter process at reduced pressure of $10 \mathrm{MPa}$ (Table 6). We noticed the advantage of a contemporaneous application of pressure and temperature, characteristic of SPS and hot-pressing in comparison to traditional sintering techniques, in which the powders are first compressed and then heated. A slight improvement of the thermal properties was observed for a reduced pressure during the cooling phase. 
Table 6. Investigation of different pressure profiles. Effect on the TC, CTE and density of the composites.

\begin{tabular}{|c|c|c|c|c|}
\hline & $\mathrm{TC}(\mathrm{x}, \mathrm{y}) / \mathrm{W} \mathbf{m}^{-1} \mathbf{K}^{-1}$ & $\mathrm{TC}(\mathrm{z}) / \mathrm{W} \mathrm{m}^{-1} \mathrm{~K}^{-1}$ & CTE $(x, y, z) / p p m K^{-1}$ & Density / $\mathrm{kg} \mathrm{m}^{3}$ \\
\hline 50-50-2 МPa & 345 & 44 & 11,0 & 2370 \\
\hline 50-2-2 MPa & 290 & 36 & 11,5 & 2320 \\
\hline $10 \mathrm{MPa}$ & 360 & 36 & 11,5 & 2370 \\
\hline
\end{tabular}

We further investigated the oxidation effect by exposing the powder mixture to air at $150^{\circ} \mathrm{C}$ for $24 \mathrm{~h}$, which had no deleterious effect on the sintered samples. Finally, we measured TC of CTE of larger samples machined to smaller size and different shape. Here, we observed over $50 \%$ higher z-TC than in the thin disc-shaped samples and slightly higher CTE.

\section{Conclusion}

We sintered metal matrix composites with aluminium alloy matrices and a mixture of pitch based carbon fibres and graphite flakes as fillers by Spark Plasma Sintering. The uniaxial pressing orients the fillers leading to high thermal conductivity in a plane $\left(330-350 \mathrm{~W} \mathrm{~m}^{-1} \mathrm{~K}^{-1}\right)$. The in-plane thermal expansion was reduced by adding carbon fibres, the through-plane expansion by addition of graphite flakes. With an optimised carbon fibre to graphite ratio, an isotropic reduction of the thermal expansion was achieved (11-14 $\mathrm{ppm} \mathrm{K}^{-1}$ ). By substitution of part of the filler with silicon, higher isotropy of the material and significantly higher tensile strength were achieved (up to $95 \mathrm{MPa}$ ). A magnesium alloy matrix was used to produce very low density composites $\left(<2000 \mathrm{~kg} \mathrm{~m}^{3}\right)$, pure aluminium and copper were used to maximise the thermal conductivity (in-plane CTE approaching $500 \mathrm{~W} \mathrm{~m}^{-1} \mathrm{~K}^{-1}$ for the copper matrix). Finally, we showed that the high heating rate and the current flow of the SPS are not necessary to achieve the optimal thermal properties. A similar composite material was sintered by hot-pressing, which requires simpler and cheaper equipment.

\section{Acknowledgements}

VO acknowledges the Evonik Foundation for the financial support. We acknowledge M. Wolff from the Helmoltz-Zentrum Geesthacht for providing the Mg-0.9Ca powders, Ecka Granules GmbH for the aluminium powders and the Nippon Graphite Fiber Corporation for the carbon fibres. We thank P. Leibner from the Max Planck Institute of Colloids and Interfaces for use of their equipment for tensile tests.

\section{Conflict of interests}

The authors declare that they have no conflict of interest. 


\section{Supplementary information}

Supplementary materials are provided regarding the production method by SPS as well as on the thermal characterisation.

\section{References}

1. Carlson RO, Glascock HH, Webster HF, Neugebauer CA (1984) Thermal expansion mismatch in electronic packaging. In: MRS Proc. Cambridge Univ Press, p 177

2. Chung DDL (1995) Materials for electronic packaging. Butterworth-Heinemann, Woburn (MA)

3. Rawal S (2001) Metal-Matrix Composites for Space Applications. JOM J Miner Met Mater Soc 53:14-17. doi: 10.1007/s11837-001-0139-Z

4. Cornie JA, Zhang S, Desberg R, Ryals M (2003) Discontinuous Graphite Reinforced Aluminum, and Copper Alloys for High Thermal Conductivity-Thermal Expansion Matched Thermal Management Applications. Met Matrix Compos LLC 7.

5. Chen JK, Huang IS (2013) Thermal properties of aluminum-graphite composites by powder metallurgy. Compos Part B Eng 44:698-703. doi: 10.1016/j.compositesb.2012.01.083

6. Etter T, Papakyriacou M, Schulz P, Uggowitzer PJ (2003) Physical properties of graphite / aluminium composites produced by gas pressure infiltration method. Carbon N Y 41:1017-1024. doi: 10.1016/S0008-6223(02)00448-7

7. Hutsch T, Schubert T, Schmidt; J, et al (2010) Innovative Metal-Graphite Composites as Thermally Conducting Materials. In: Proc. Powder Metall. World Congr. Exhib. PM2010. pp 361-368

8. Fukushima H (2010) High-thermal-conductivity graphite-particles-dispersed-composite and its production method.

9. Boden A, Boerner B, Kusch P, et al (2014) Nanoplatelet size to control the alignment and thermal conductivity in copper-graphite composites. Nano Lett 14:3640-3644. doi: 10.1021/n1501411g

10. Firkowska I, Boden A, Boerner B, Reich S (2015) The Origin of High Thermal Conductivity and Ultralow Thermal Expansion in Copper-Graphite Composites. Nano Lett 15:4745-4751. doi: 10.1021/acs.nanolett.5b01664

11. Oddone V, Boerner B, Reich S (2017) Composites of aluminum alloy and magnesium alloy with graphite showing low thermal expansion and high specific thermal conductivity. Sci Technol Adv Mater 18:180-186. doi: 10.1080/14686996.2017.1286222

12. Bai H, Xue C, Lyu J, et al (2018) Thermal conductivity and mechanical properties of flake graphite/Al composite with a SiC nano-layer on graphite surface. Compos Part A 106:42-51. doi: 


\subsection{6/j.matdes.2016.06.122}

13. Korb G, Koráb J, Groboth G (1998) Thermal expansion behaviour of unidirectional carbon-fibrereinforced copper-matrix composites. Compos Part A 29:1563-1567. doi:

http://dx.doi.org/10.1016/S1359-835X(98)00066-9

14. Koráb J, Štefánik P, Kavecký Š, et al (2002) Thermal conductivity of unidirectional copper matrix carbon fibre composites. Compos - Part A 33:577-581. doi: 10.1016/S1359835X(02)00003-9

15. Silvain J-F, Veillère A, Lu Y (2014) Copper-Carbon and Aluminum-Carbon Composites Fabricated by Powder Metallurgy Processes. J Phys Conf Ser 525:12015. doi: 10.1088/17426596/525/1/012015

16. Oddone V, Reich S (2017) Thermal properties of metal matrix composites with planar distribution of carbon fibres. Phys status solidi - Rapid Res Lett 1700090:1700090. doi: 10.1002/pssr.201700090

17. Jagannadham K (2011) Orientation dependence of thermal conductivity in copper-graphene composites. J Appl Phys 110:74901. doi: 10.1063/1.3641640

18. Cho J, Chen JY, Daniel IM (2007) Mechanical enhancement of carbon fiber/epoxy composites by graphite nanoplatelet reinforcement. Scr Mater 56:685-688.

19. Qin W, Vautard F, Drzal LT, Yu J (2015) Mechanical and electrical properties of carbon fiber composites with incorporation of graphene nanoplatelets at the fiber--matrix interphase. Compos Part B Eng 69:335-341.

20. Thongruang W, Spontak RJ, Balik CM (2002) Correlated electrical conductivity and mechanical property analysis of high-density polyethylene filled with graphite and carbon fiber. Polymer (Guildf) 43:2279-2286.

21. Prieto R, Molina JM, Narciso J, Louis E (2008) Fabrication and properties of graphite flakes/metal composites for thermal management applications. Scr Mater 59:11-14. doi: 10.1016/j.scriptamat.2008.02.026

22. Dresselhaus MSs of fullerenes and carbon nanotubes: their properties and applications, Dresselhaus G, Eklund PC (1996) Science of Fullerenes and Carbon Nanotubes: Their Properties and Applications. Academic press

23. Minus ML, Kumar S (2005) The processing, properties, and structure of carbon fibers. J Miner Met Mater Soc 57:52-58. doi: 10.1007/s11837-005-0217-8

24. Muhammad WNAW, Sajuri Z, Mutoh Y, Miyashita Y (2011) Microstructure and mechanical 
properties of magnesium composites prepared by spark plasma sintering technology. J Alloys Compd 509:6021-6029. doi: 10.1016/j.jallcom.2011.02.153

25. Zhou Y, Hirao K, Yamauchi Y, Kanzaki S (2003) Effects of heating rate and particle size on pulse electric current sintering of alumina. Scr Mater 48:1631-1636.

26. Olevsky EA, Kandukuri S, Froyen L (2007) Consolidation enhancement in spark-plasma sintering: Impact of high heating rates. J Appl Phys 102:114913.

27. Munir Z a., Anselmi-Tamburini U, Ohyanagi M (2006) The effect of electric field and pressure on the synthesis and consolidation of materials: A review of the spark plasma sintering method. $\mathrm{J}$ Mater Sci 41:763-777. doi: 10.1007/s10853-006-6555-2

28. Donaldson AB, Taylor RE (1975) Thermal diffusivity measurement by a radial heat flow method. J Appl Phys 46:4584-4589.

29. Segl J, Edtmaier C, Rosenberg E (2016) Influence of Processing Parameters on the Thermal Conductivity Behavior in Al- diamond MMCs. In: World PM2016. pp 1-7

30. Wolff M, Ebel T, Dahms M (2010) Sintering of magnesium. Adv Eng Mater 12:829-836. doi: 10.1002/adem. 201000038

31. Buerschaper RA (1944) Thermal and electrical conductivity of graphite and carbon at low temperatures. J Appl Phys 15:452-454.

32. Zahra a. M, Zahra CY, Jaroma-Weiland G, et al (1995) Heat capacities of aluminium alloys. J Mater Sci 30:426-436. doi: 10.1007/BF00354407

33. Mounet N, Marzari N (2004) High-accuracy first-principles determination of the structural, vibrational and thermodynamical properties of diamond, graphite, and derivatives. arXiv 17. doi: 10.1103/PhysRevB.71.205214

34. Ueno T, Yoshioka T, Ogawa J, et al (2009) Highly thermal conductive metal/carbon composites by pulsed electric current sintering. Synth Met 159:2170-2172. doi:

10.1016/j.synthmet.2009.10.006

35. Daoud A (2004) Wear performance of 2014 Al alloy reinforced with continuous carbon fibers manufactured by gas pressure infiltration. Mater Lett 58:3206-3213. doi: 10.1016/j.matlet.2004.06.012

36. Kwon H, Estili M, Takagi K, et al (2009) Combination of hot extrusion and spark plasma sintering for producing carbon nanotube reinforced aluminum matrix composites. Carbon N Y 47:570-577. doi: 10.1016/j.carbon.2008.10.041

37. Etter T, Schulz P, Weber M, et al (2007) Aluminium carbide formation in interpenetrating 
graphite/aluminium composites. Mater Sci Eng A 448:1-6. doi: 10.1016/j.msea.2006.11.088

38. Monje IE, Louis E, Molina JM (2013) Optimizing thermal conductivity in gas-pressure infiltrated aluminum/diamond composites by precise processing control. Compos Part A Appl Sci Manuf 48:9-14. doi: 10.1016/j.compositesa.2012.12.010 